\title{
There's no place like home: The associations between residential attributes and family functioning
}

Carly M. Thornock

Brigham Young University - Provo

Larry J. Nelson

Brigham Young University - Provo, larry_nelson@byu.edu

Chris L. Porter

Brigham Young University - Provo

Cortney A. Evans-Stout

Brigham Young University - Provo

Follow this and additional works at: https://scholarsarchive.byu.edu/facpub

Part of the Other Social and Behavioral Sciences Commons

\section{Original Publication Citation}

*Thornock, C. M., Nelson, L. J., Porter, C. L., \& Evans, C. A. (2019). There's no place like home:

The associations between residential attributes and family functioning. Journal of

Environmental Psychology, 64, 39-47.

\section{BYU ScholarsArchive Citation}

Thornock, Carly M.; Nelson, Larry J.; Porter, Chris L.; and Evans-Stout, Cortney A., "There's no place like home: The associations between residential attributes and family functioning" (2019). Faculty Publications. 4707.

https://scholarsarchive.byu.edu/facpub/4707

This Peer-Reviewed Article is brought to you for free and open access by BYU ScholarsArchive. It has been accepted for inclusion in Faculty Publications by an authorized administrator of BYU ScholarsArchive. For more information, please contact ellen_amatangelo@byu.edu. 


\title{
There's no place like home: The associations between residential attributes and family functioning ${ }^{\text {is }}$
}

\author{
Carly M. Thornock, Larry J. Nelson*, Chris L. Porter, Cortney A. Evans-Stout \\ Brigham Young University, Provo, UT, USA
}

\section{A R T I C L E I N F O}

\section{Keywords:}

Family functioning

Crowding

Density

Home

Space

\begin{abstract}
A B S T R A C T
The purpose of this study was to examine the ways in which actual (e.g., density) and perceived (e.g., crowding and distance) elements of the spatial home environment act as predictors of family functioning. Data were gathered from 164 families whose child was attending a university's preschool/kindergarten facility in a midsized community in the Western United States. Structural equation modeling (SEM, AMOS 19.0) was employed to examine the strength of the relations within the model. Results showed that though actual elements of the home (i.e., density) affect family functioning outcomes, perceptions of the home environment (e.g., crowding and distance) were especially influential as mediating the link between density and aspects of family functioning. Findings suggest that how individuals perceive their home environment has more of an effect on family functioning than actual home characteristics.
\end{abstract}

\section{Introduction}

A growing literature demonstrates the important contribution of the physical properties of environments that facilitate family dynamics and potentially influence children's development (e.g., Evans, 2006; Thornock, Nelson, Robinson, \& Hart, 2013; Wachs, 1979, 1988, 1989). Interestingly, in a study by Farrow, Taylor, and Golding (2010), they followed 170 families over the course of a year showing that mothers, fathers, and infants spend an average of 18.4 (76.7\%), $14.7(61.3 \%)$ and $19.3(80.4 \%)$ hours per day in the home, respectively, making the home the primary place where family members spend their time. Given the amount of time spent in the home, it is important to understand the ways in which the physical environment influences the people who live there and the processes that occur there. The home has long been studied both in terms of its social atmosphere (i.e., parenting, routines, housework, conflict, etc.) and as a canvas for architecture and interior design (i.e., construction, aesthetic combinations, color, etc.). The scholarly intersection of the two fields of architecture/design and family studies has continued to grow, with particular impetus given to better understanding the way the physical environment might contribute to family functioning above and beyond the social environment (e.g., Wachs \& Chan, 1986). However, while an understanding of the correlates between behavior and the physical environment has increased, additional work is needed to better understand, as Evans (2006) states, the "underlying mechanisms [that] account for [the] developmental impact of the physical environment on human behavior" (p.439). Therefore, this study was designed to examine the association between physical characteristics of the home (both actual and perceived) in relation to family processes. Based on work by Epstein, Baldwin, and Bishop (1983), four elements of family functioning seem to be particularly relevant in examining family well-being which may also be sensitive to the influence of the physical environment. These processes include the dimensions of affective responsiveness, emotional expression, acceptance, and decision-making. Thus, given the developmental benefits of healthy family functioning, it seems important to identify the way in which the physical features of the home may facilitate these processes. Therefore, the purpose of this study was to explore how physical factors of the home, both actual and perceived, are related to the way families with young children interact with one another.

\section{Theoretical background}

The present study is grounded in two primary theories originating from design and the social sciences. The first theoretical framework falls within the field of study known as environment stimulated

\footnotetext{
The authors express appreciation for the financial support of the Family Studies Center and the College of Family, Home, and Social Sciences at Brigham Young University.

* Corresponding author. 2091 JFSB Provo, UT, 84602., USA.

E-mail address: larry_nelson@byu.edu (L.J. Nelson).
} 
behavior. This framework builds conceptually around the construct of environmental affordances. Affordances describes how the properties of the environment (i.e., a home) provide/afford and/or potentially restrict opportunities for either positive or negative interactive processes related to both individual and relational development within that setting (Gibson, 1977; Miller, Shim, \& Holden, 1998). Affordances relate to the multifaceted dynamics of a space or physical item that allows one to execute a particular class of behaviors. For instance, a stove affords cooking, a chair affords sitting, and large, frequented rooms afford gathering. Researchers have found that affordances are not necessarily the properties of the objects themselves, but rather involve the intersection of person, object, and even space (Chemero, 2003; Michaels, 2003). While affordances and the experience of life space (Lewin, Heider, \& Heider, 1936) have been shown to be individually perceived even within the home, little research has examined how variations in home affordances might be linked to how families as a unit interact with their home environment.

The second theory that explicates ways in which space defines social interactions and impacts human development is the optimal stimulation model. This model postulates that human functioning is affected by environmental stimulation. If stimulation levels are too low or too high, people respond negatively, but an optimal level of stimulation allows for healthy growth, affect, performance, and health (Evans \& Cohen, 1987). Environmental elements that have been shown to cause stress responses (i.e., overstimulation) are noise, crowding, change, and ambiguity (Cohen, Krantz, Evans, Stokols, \& Kelly, 1981; Evans \& Cohen, 1987; Kaminoff \& Proshansky, 1982; Wohlwill, 1974). An abundance of these stressful environmental factors has the potential to harm familial relationships, however, when a home mediates the effects of stressful environmental harms (e.g., allowing room for each family), family functioning and behavior are better able to thrive.

\section{Physical space and family functioning}

Not only are there theoretical reasons to expect a connection between physical aspects of the home and the familial processes that occur therein, a growing body of research suggests links between the two, with scholars looking at the role of the home environment as a social and physical construct (e.g., Wachs \& Chan, 1986). For instance, using the Confusion, Hubbub, and Order Scale (CHAOS) to assess the home environment (Matheny, Wachs, Ludwig, \& Phillips, 1995; Shamama-tus-Sabah \& Gillani, 2011), researchers have found that household chaos (i.e., environmental confusion, ambient noise, crowding, commotion, and untidiness) is linked to child conduct problems, decreased study and social skills, (Shamama-tus-Sabah \& Gillani, 2011), family cooperation issues (e.g., decision making; Dumas et al., 2010), and increased authoritarian parenting (Coldwell, Pike, \& Dunn, 2006). Although it is important to examine how confusion, noise, commotion, and clutter might impact individuals within families and family functioning, these factors still do not address the role that the spatial/physical elements of the home plays.

The research that has explored the associations between the specifics of the physical home and family has often focused on extreme or special familial circumstances such as disorder, disability, or safety (Emerson et al., 2000; Kopec \& LaCapra, 2008; Lewis \& Turner, 2006). Although it is certainly important to understand how physical aspects of the home may influence the safety and quality of life for special populations and specific individuals (e.g., elderly, children with disabilities), there is a need to better understand how the structure of the home might affect (positively or negatively) normal family routines and processes.

Family functioning is an umbrella term referring to family processes including parenting, family relation characteristics, emotional warmth, routines, rituals, and family roles (Fiese et al., 2002; Gorman-Smith, Henry, \& Tolan, 2004). Healthy family functioning and connectedness is often characterized by a warm, cohesive interaction pattern. Healthy family functioning has been associated with a myriad of positive benefits. For instance, healthy family functioning has been shown to be a protective factor against child violence and problem behaviors in general (Gorman-Smith et al., 2004; LeBlanc, Self-Brown, Shephard, \& Kelley, 2011), and a contributor to child exploration and creativity (Miller \& Gerard, 1979).

Taken together, the extant literature demonstrates that family functioning is an important foundation upon which identity, values, and motivation are built. Since family processes are infused with meaning and are associated with marked outcomes, it is important to consider how the physical elements of the home (and perceived aspects of the physical home, as they may also affect the way people behave in certain spaces beyond the impact of the actual features of the home) may be related to family involvement and functioning. Therefore, the overall purpose of this study was to examine the ways in which aspects of the physical home environment (i.e., density) and perceived aspects of the home environment (i.e., feeling too crowded, too spread out) may be related to family processes (i.e., family affective responsiveness, emotional expressiveness, acceptance, decision making) in families with young children.

\subsection{Spatial features of the home}

Density. Density is a common factor used in describing spatial needs of individuals and families. Size and density of a home are related, though they differ in that size generally is measured in square foot increments and is a measure that remains constant regardless of occupant load. Density, however, is a measure of the ratio of individuals to an area (usually square feet), or, as has been examined (Maxwell, 2003), space per person. A measure of density is helpful to consider in lieu of a strict square footage analysis since the home environment, as a whole is dynamic, varying according not only in size but also in the occupant load and activity levels that occur in it.

Density has been found to be correlated with physiological arousal and stress, being manifest in areas such as elevated heart rate, blood pressure, skin conductance, mood change, and aggressive tendencies (McAndrew, 1993). Density affects human functioning in people of all ages, though its effects are especially prominent in children (Baum \& Koman, 1976; Evans, Lepore, \& Schroeder, 1996; Evans, Maxwell, \& Hart, 1999). For instance, Maxwell (1996, 2003) determined that children in high-density (person-to-space ratio) homes and child-care centers have increased susceptibility to behavioral issues. Additionally, Maxwell (2003) found that children in situations where there is less space per person in classroom settings demonstrated poorer academic achievement (especially for girls), and classroom behavior (especially for boys). Further, a few studies have found negative correlations between residential density and school achievement, potentially due to distraction when studying at home (Maxwell, 1996, 2003; Saegert, 1982). Finally, researchers have found that parents in crowded homes are less responsive to their children, and thus speak in less complex, sophisticated ways to their children (Evans et al., 1999). From these studies, it seems that density has the potential to contribute to individual and, potentially, familial health and well-being, with lower density contributing positive effects and higher density having a negative impact. Therefore, the first purpose of this study was to evaluate the direct links between home density and family functioning.

\subsection{Perceptions of space in the home}

Although actual elements of the home, such as density, are important factors in the present study, perceptual interpretations of the spatial home environment may similarly influence the family. Physical attributes of the residential environment are usually objective, yet how one subjectively feels about those attributes may impact his or her attitudes and behavior to a greater extent than the physical feature itself. Specifically, crowding (feeling too close to others) or distance (how 
distant one feels from others in his or her space) are two environmental factors that have the capacity for differential interpretation based on individuals' perceptions of these physical dimensions. In other words, the same home may be viewed by some as too crowded but lead others to feel too distant. Some researchers mention the likelihood of distance being the antithesis to crowding but there is evidence that perceived crowding and perceived distance are, in fact, different ways of feeling about the actual space (e.g., Gabe \& Williams, 1986). In other words, some may have a greater problem with too little space while, for others, little space may not be ideal but it may not be as problematic for them as feeling too spread out from others due to availability of space. As a result, we deemed it important to examine the two constructs (e.g., crowding and felt distance) as unique perceptions of actual space (density) in order to more fully examine how both aspects of family members' perceptions may be linked to family interactions.

Again, there is evidence to suggest that perceptions of space (i.e., crowding, distance), even more than the actual amount of space, are related to a number of important outcomes (e.g., Bell, Greene, Fisher, \& Baum, 2001; Kopec, 2006). In other words, although it is most certainly the case that the more people in an area, the more likely one is to feel crowded (e.g., Knowles, 1983), the perception of crowding or distance may vary from person to person (Heft, 2001; Lewin et al., 1936), and might be more important to individual and family well-being than actual density. For example, researchers found that prison crowding was related to psychological stress for inmates, but prison density itself was not related to inmate distress (Baum \& Koman, 1976; Schaeffer, Baum, Paulus, \& Gaes, 1988). When people feel crowded, researchers have found adverse effects. For example, when riding transportation, the stress response is triggered when people feel that their personal space is violated (Evans \& Wener, 2007), and children experience mental health concerns when living in crowded multi-family homes (Evans, Lercher, \& Kofler, 2002).

Similarly, distance (or isolation) in its extreme, is related to death (House, 2001). In medical patients, particularly those who are aged, isolation leads to hindered recovery and predicted mortality (Brummett et al., 2001). In most people's reality, feeling isolated is related to a perceived lack of interaction, perhaps due to low density. If children are lacking familial interaction, socialization issues are expected to emerge (Zigler \& Finn Stevenson, 1993). For example, children have a hard time learning to behave in social situations when family interaction is sparse.

In sum, there is growing evidence that the perception of space is just as, or more important, than the actual amount of space, however, research is limited in examining the home as the context for "space." Indeed, perceptions of space might mediate the link between the actual space (e.g., density) and family functioning. Although prior work examining the impact of crowding and distance on individual well-being in non-home contexts is enlightening, it cannot be assumed that the findings can be generalized to what might be occurring in the home. Conceptually, the home is a particularly important setting to understand the impact of space (actual and perceived) as prior work suggests that family interaction is facilitated by homes environments that a) accommodate family activities, b) accommodate multiple activities in the same location, c) facilitate household tasks, and d) maximize aesthetic appeal of family spaces (Miller \& Maxwell, 2003).

It is also important to study the effects of perceptions of space (crowding and distance) within the home because of the unique features of the home compared to other types of environments (i.e., prisons, hospitals, schools, transportation, offices). First, as opposed to most environments, the people within the home tend to be related. The goals of related individuals (e.g., love, protection, socializing) tend to be very different from non-related individuals in other contexts. Second, many non-home spaces serve, or afford, very specific functions whereas the home serves a multitude of functions. For example, offices at places of employment are rather narrowly intended for work. Hospitals afford spaces for treatment of the sick and physical recovery.
The home, however, serves multiple functions including recreation, learning, rest, recovery, eating, work, teaching, and many more. Hence, in this complex setting, the impact of crowding and distance has the potential to influence numerous aspects of individual and relational well-being. Taken together, although researchers have examined how perceptions of space (i.e., crowding, distance) influence the people and processes that occur within that space in non-home settings, the home is a unique setting that deserves particular attention to the effects of space, both actual and perceptions thereof. Hence, the second purpose of the study was to explore the degree to which perceptions of space, specifically crowding and distance, might mediate the relations between actual elements of home space (density) and aspects of family functioning (family affective responsiveness, family emotional expression, family acceptance, family decision making) in families with young children.

Furthermore, evidence repeatedly suggests that there are temperamental differences, on average, between boys and girls with boys being more active and girls exhibiting more effortful control (i.e., the regulatory component of temperament allowing a child to inhibit impulses and manage negative emotion; see Else-Quest, Hyde, Goldsmith, \& Van Hulle, 2006 for a review). Not only has research shown that aspects of temperament tend to elicit various types of parenting directly (e.g., Belsky, Bakermans-Kranenburg, \& Ijzendoorn, 2007; Rubin, Nelson, Hastings, \& Asendorf, 1999) but that aspects of temperament mediate the way in which features of the home impact family processes. For example, young children's emotionality has been found to mediate the link between clutter in the home and maternal use of authoritarian (harsh, punitive, controlling) parenting (Thornock et al., 2013). Given gender differences in features of temperament (e.g., activity level, effortful control) that may affect how individuals feel in the space they are in, we felt it important to explore for possible differences based on the biological sex of the child.

In summary, the first purpose of this study was to evaluate the direct links between home density and family functioning in families with young children. Based on growing work that less space-per-person (low density) is linked to negative processes within the home (Evans et al., 1999), it was hypothesized that actual home density would be linked to family functioning. Specifically, it was hypothesized that the more space-per-person within the home would be positively related to affective family responsiveness, emotional expression, acceptance, and decision-making. The second purpose of the study was to explore the degree to which perceptions of space, specifically crowding and distance, might mediate the relations between actual elements of home space (density) and aspects of family functioning. It was hypothesized that crowding and distance, respectively, would serve as mediators in that more space per person (low density) would predict lower perceptions of crowding and higher perceptions of distance, respectively, while it was expected that both crowding and distance would predict lower levels of family functioning. Finally, the direct and indirect (via crowding and distance) links between density (i.e., space-per-person) and family functioning were examined in families with young daughters and families of young sons, respectively. Based on evidence that boys are temperamentally more active while girls possess greater effortful control, it was believed that gender may play a role in how mothers perceive the space they are in. Specifically, it was expected that the previously hypothesized relations regarding the mediating role of perceptions of space (i.e., crowding and distance, respectively) would be particular strong for mothers of boys.

\section{Method}

\subsection{Participants and procedure}

Participants in this study were drawn from a larger study examining the ways in which parenting, the parenting environment, and child characteristics interact to influence children's well-being and behavior 
Table 1

Correlations between all variables.

\begin{tabular}{|c|c|c|c|c|c|c|c|}
\hline & Income & Density & Crowding & Distance & Family Acceptance & Family Emotional Expressiveness & Family Decision Making \\
\hline Income & - & & & & & & \\
\hline Density (Space per person) & $-.619^{* *}$ & - & & & & & \\
\hline Crowding & $-.392^{* *}$ & $-.458^{* *}$ & - & & & & \\
\hline Distance & $.158^{*}$ & $.396^{* *}$ & $-.210^{* *}$ & - & & & \\
\hline Family Acceptance & .002 & .062 & $-.225^{* *}$ & -.126 & - & & \\
\hline Family Emotional Expressiveness & .066 & $.192^{*}$ & $-.188^{*}$ & -.031 & $.470^{* *}$ & - & \\
\hline Family Decision Making & .149 & .178 & $-.325^{* *}$ & -.016 & $.518^{* *}$ & $.460^{* *}$ & - \\
\hline Family Responsiveness & .059 & .153 & $-.189 *$ & -.100 & $.520^{* *}$ & $.462^{* *}$ & $.404^{* *}$ \\
\hline
\end{tabular}

$* * \mathrm{p}<.01 * \mathrm{p}<.05$

in peer settings. Children and their parents were recruited from university-based early childhood classrooms (preschool and kindergarten) in the western United States during three consecutive teaching sessions (Winter, Summer, Fall). Across all classrooms, there was a $71 \%$ participation rate of children and at least one parent. Participants in the study were mothers with complete data for the variables utilized in the current study resulting in 164 mothers with an average age of 34.03 years (ranging from 24 to 52 ) and whose children [54\% male $(\mathrm{N}=89)$ and $46 \%$ female $(\mathrm{N}=75)]$ were ages 4-6 $(M=54$ months, $S D=18.49$ ). The average household income was $\$ 40,000-\$ 50,000$. Mothers, on average, had completed a Bachelor degree. Regarding the home and home environment, the average number of bedrooms in the participants' homes was 3.97 ( $S D=1.33$; range $1-10$ ), the average number of overall rooms (not counting a garage) was $10.90(S D=3.88$; range: 1-23), and the average number of people living in the home was $5.19(S D=1.34$; range: $3-10)$. Surveys were sent to the parents of each child using Qualtrics, an online survey program. Mothers were able to consent and fill out answers to survey questions from their home or work computers at their convenience using an individualized link. IRB approval was obtained for the larger project of which this study was a part.

\subsection{Measures}

Home density. Home density was measured via two open-ended questions: "How many people live in your house?" and "How large is your home, in square feet?" Home density was then calculated by dividing the amount of square-footage in the household by total number of people that live there resulting in a score representing the number of square-feet-per-person $(M=497.84$ sqft-per-person; $S D=258.59$; range: 125-1266.67). Hence, for this study, higher scores on density reflect more space per person.

Crowding. Perceived crowding was a variable comprised of two questions using a Likert scale. First, "I feel crowded in my house," was answered according to options ranging from extremely untrue to extremely true (values of 1-7). The second question, "I wish that the separate rooms in my home were more closed off," was answered using a 6-point scale ranging from strongly agree to strongly disagree. Given that these two items were strongly correlated $(r=0.66)$, they were averaged to create a scale of perceived crowding $(M=2.93$; $S D=1.57)$.

Physical distance. To determine felt distance (i.e., the degree to which family members feel separated unnecessarily from each other) the item "I feel like our family is too spread out within our home" was measured using a 6-point Likert scale ranging from strongly agree to strongly disagree $(M=2.18 ; S D=1.16)$.

Family functioning. Family functioning was measured using 19 items from the McMaster Family Assessment Device (FAD, Epstein et al., 1983). Items included the General Functioning and Affective Responsiveness subscales. Responses ranged from 1 (strongly disagree) to 4 (strongly agree). General Family Functioning was broken up to reflect three distinct subscales: Emotional Expression (e.g., "we avoid discussing our fears and concerns," 3 items, factor loadings ranging from 0.64 to
0.72; $\alpha=0.72$ ), Acceptance (e.g., "family members feel accepted for what they are," 4 items, factor loadings ranging from 0.62 to 0.85 ; $\alpha=0.83$ ), and Decision Making (e.g., "making decisions is a problem for our family," 3 items, factor loadings ranging from 0.67 to $0.70 ; \alpha=0.78$ ). Family Affective Responsiveness (e.g., "we express tenderness," 5 items, factor loadings ranging from 0.38 to $0.83 ; \alpha=0.72$ ) reflects the degree and prevalence of expressed affection and emotion in the family. Participants answered how much they agree or disagree with statements about their family with response options ranging from 1 (strongly disagree) to 4 (strongly agree). Items were coded so that higher scores indicate better family functioning.

Income. Participants indicated their current household income on a scale ranging from 1 to $10(1=$ no income; $5=\$ 25,000-\$ 29,000$; $10=$ over $\$ 100,000 ; M=7.86 ; S D=2.09 ;$ range $=1-10)$. Because socioeconomic status is potentially confounded with home size and home-perceptions we included income as a control in the current analysis.

\section{Results}

Preliminary analyses were conducted using the software program SPSS 18.0 (Statistical Package for the Social Sciences) to determine the correlational strength of the variables included in the study (see Table 1). Home density refers to the actual home environment while crowding and distance refer to the perceived home environment. The three endogenous variables for family functioning included: affective responsiveness, emotional expressiveness, acceptance, and decisionmaking. Descriptive statistics for all variables are found in Table 2.

\subsection{Analysis and model fit}

After initial analysis, we used AMOS 20.0 to first, conduct a confirmatory factor analysis of the endogenous family functioning variables (i.e., family responsiveness, emotional expressiveness, family acceptance, and family decision-making), second, to examine direct effects between home density and family functioning variables, third, to see if perceptions of the home environment (i.e., crowding and distance) mediated these direct effects, and fourth, to examine differences in these paths for parents of boys vs. girls. Income was included as a control variable in all path models.

Table 2

Descriptive Statistics.

\begin{tabular}{lllll}
\hline & Mean & SD & Minimum & Maximum \\
\hline Income & 7.86 & 2.09 & 1.00 & 10.00 \\
Density (Space per person) & 497.84 & 258.59 & 125.00 & 1266.67 \\
Crowding & 2.93 & 1.57 & 1.00 & 7.50 \\
Distance & 2.17 & 1.19 & 1.00 & 7.00 \\
Family Emotional Expression & 4.43 & .52 & 2.33 & 5.00 \\
Family Acceptance & 4.40 & .51 & 2.75 & 5.00 \\
Family Decision Making & 4.14 & .65 & 2.67 & 5.00 \\
Family Affective Responsiveness & 4.54 & .47 & 2.40 & 5.00 \\
\hline
\end{tabular}


For each model, fit indices were used to assess the overall model fit of the structural equation model. Model fit was assessed using three fit indicators, explained by Hooper, Coughlan, and Mullen (2008) as follows: (1) The Comparative Fit Index (CFI) compares how much better a model fits the data compared with a null model. (2) The Tucker-Lewis Index (TLI), which contains a penalty for lack of parsimony. The CFI and TLI should be equal to or greater than 0.9 (Hu and Bentler (1999) have suggested TLI $\geq 0.95$ ), indicating that $90 \%$ of the co-variation in the data can be reproduced by the given model. (3) The Root Mean Square Error of Approximation (RMSEA) adjusts for both sample size and number of degrees of freedom. Good model fit is obtained if RMSEA is less than or equal to 0.05 and adequate fit if RMSEA is less than or equal to 0.08 .

First, we conducted a confirmatory factor analysis on the endogenous family functioning variables which verified the factor structure of the latent variables in the model $\left(\chi^{2}=108.08, p<.05\right.$; $\mathrm{CFI}=0.96$; $\mathrm{TLI}=0.93$; RMSEA $=0.05$ ). Given the variables fit the data well, we proceeded with two separate structural equation models: the first examined the direct effects of home density (a measure of the actual home environment) on family functioning variables while the second examined the role of the perceived home environment (i.e., crowding and distance) in mediating these relationships.

\subsection{Examination of relationships between home variables and family functioning}

Direct effects. Direct effects between home density (space per person) and family functioning variables were specified in a structural equation model. This model fit the data well $\left(\chi^{2}=152.47, d f=105\right.$, $\mathrm{p}<.01$; CFI $=0.95$; TLI $=0.94$; RMSEA $=0.05$ ) and resulted in significant pathways between home density and familial emotional expressiveness $(\beta=0.19, p<.05,95 \%$ CI $[0.01,0.34])$ as well as between home density and family decision-making $(\beta=0.22, p<.01$, 95\% CI [0.09, 0.34]).

Indirect effects. In order to more fully examine these relationships, we utilized bias corrected bootstrap analysis (Preacher \& Hayes, 2008) to examine how home density may be indirectly related to family functioning through both participants' perceptions of crowding in the home as well as their perceptions of physical distance between people in the household. In addition to these indirect paths, all other pathways from endogenous to exogenous variables were modeled. Fig. 1 represents the resulting significant pathways. The model showed a good fit with the data $\left(\chi^{2}=193.04, d f=133, \mathrm{p}<.01 ; \mathrm{CFI}=0.95\right.$; TLI $=0.93$; RMSEA $=0.05$ ) and results indicate that home density (space per person) was related to both perceived crowding $(\beta=-0.47$, $p<.001,95 \%$ CI $[-0.57,-0.34])$ and perceived distance $(\beta=0.38$, $p<.00195 \%$ CI $[0.23,0.52])$. Perceived crowding was significantly associated with emotional expression $(\beta=-0.32, p<.001,95 \% \mathrm{CI}$ $[-0.52,-0.15])$, family acceptance $(\beta=-0.37, p<.001,95 \%$ CI $[-0.51,-0.17])$, and family decision-making $(\beta=-0.38, p<.001$, $95 \%$ CI $[-0.62,-0.17])$. Perceived distance was related to family acceptance $(\beta=-0.23, p<.01,95 \%$ CI $[-0.45,-0.05])$. Examination of indirect effects in the model showed that the relationships between home density and family functioning were fully mediated by participant perceptions of home crowding (emotional expression: standardized indirect effect $\beta=0.11, p<.05,95 \%$ CI [0.01, 0.23]; family decisionmaking: standardized indirect effect $=0.15, p<.01,95 \%$ CI $[0.05$, $0.28]$ ). Perceived distance did not mediate any of the associations in the model.

Gender differences. Using multiple group analysis, we examined the measurement between participants with a female child vs. participants with a male child. We did this by comparing a model where the factor loadings and intercepts were constrained to be equal across child gender to an unconstrained model where factor loadings and intercepts were allowed to be freely estimated for each gender. Results indicate that the differences between the constrained vs. unconstrained model were insignificant $\left(\chi^{2}=50.23, d f=36, \mathrm{p}=.27\right.$; bootfactor $\left.=2\right)$ indicating that the structural paths for mothers of boys and mothers of girls can be compared to examine differences.

For parents of young girls, perceptions of crowding fully mediated the relationships between home density and family acceptance (standardized indirect effect $\beta=0.22, p<.01,95 \%$ CI [0.05, 0.39]), familial emotional expression (standardized indirect effect $\beta=0.23$, $p<.05,95 \%$ CI $[0.06,0.41]$ ) and, family decision-making (standardized indirect effect $\beta=0.17, p=.05,95 \%$ CI $[0.02,0.32]$ ) such that the more crowded a parent perceives the home to be the lower they score on these family functioning variables. Also, for parents of girls, perceived home distance is not significantly related to family acceptance as it was in the full model. See Fig. 2 for a representation of significant paths for mothers of girls.

For parents of young boys, on the other hand, perceived crowding only mediated the relationship from home density to family decisionmaking (standardized indirect effect $\beta=.07, p=.05,95 \%$ CI $[-0.11$, $0.25]$ ). Unlike for girls, perceived distance was related to both familial acceptance $(\beta=-0.43, p<.05,95 \%$ CI $[-0.71,-0.15])$ and to familial emotional expression $(\beta=-0.30, p<.001,95 \%$ CI $[-0.50$, $-0.10]$ ). All other paths were similar for boys vs. girls. See Fig. 3 for a representation of significant paths for mothers of boys.

\section{Discussion}

The overall goal of this study was (a) to evaluate the direct links between home density and family functioning (family affective responsiveness, emotional expression, acceptance, and decision making) in families with young children while controlling for income, (b) examine the degree to which perceptions of space, specifically crowding and distance, might mediate the relations between actual elements of home space (density) and aspects of family functioning, and (c) explore for differences in these relations in families with young daughters and families of young sons, respectively. Existing design and behavioralenvironmental research has demonstrated the effects of space on the individual (Bell et al., 2001; Kopec, 2006), yet there is a need to contribute to the growing body of work examining the ways in which the physical and design elements of the home influence the processes that occur therein (Brummett et al., 2001; Maxwell, 2003). Findings of the present study revealed that home density makes an important contribution to how parents feel about their space and how they relate to their families but, also, that perceptions of the space are critical in influencing the processes that occur within the home. Important differences based on the sex of the child were discovered as well. As we begin a discussion of these findings, it should be noted from the outset that although we will speak in terms of certain variables predicting others, all of the relations in the present study were correlational due to the cross-sectional nature of the data, which precludes definitive statements regarding directions of effect from being made.

Results revealed direct relations between home density and familial emotional expressiveness and family decision-making such that increases in space per person in the home improved these important aspects of family function. Optimal stimulation theory would suggest that appropriate levels of stimulation are necessary for healthy family interaction and these results appear to support this notion. It may be that family members may feel less guarded toward one another, and more able to express feelings and opinions more, when they do not feel like their personal spatial needs are being violated. Indeed, selective attention (intensely focusing to the exclusion of other competing stimuli) is another effect of environmental stress that can be brought about by increased density. For instance, as Evans and Maxwell (1997) indicated, increased environmental stress (a common effect of density and crowding) can encourage residents, especially children, to tune out stimuli, which might include attempts of other family members to interact. Thus, family members may be more likely to tune each other out or respond to one another in unhealthy ways (i.e., less accepting) when 


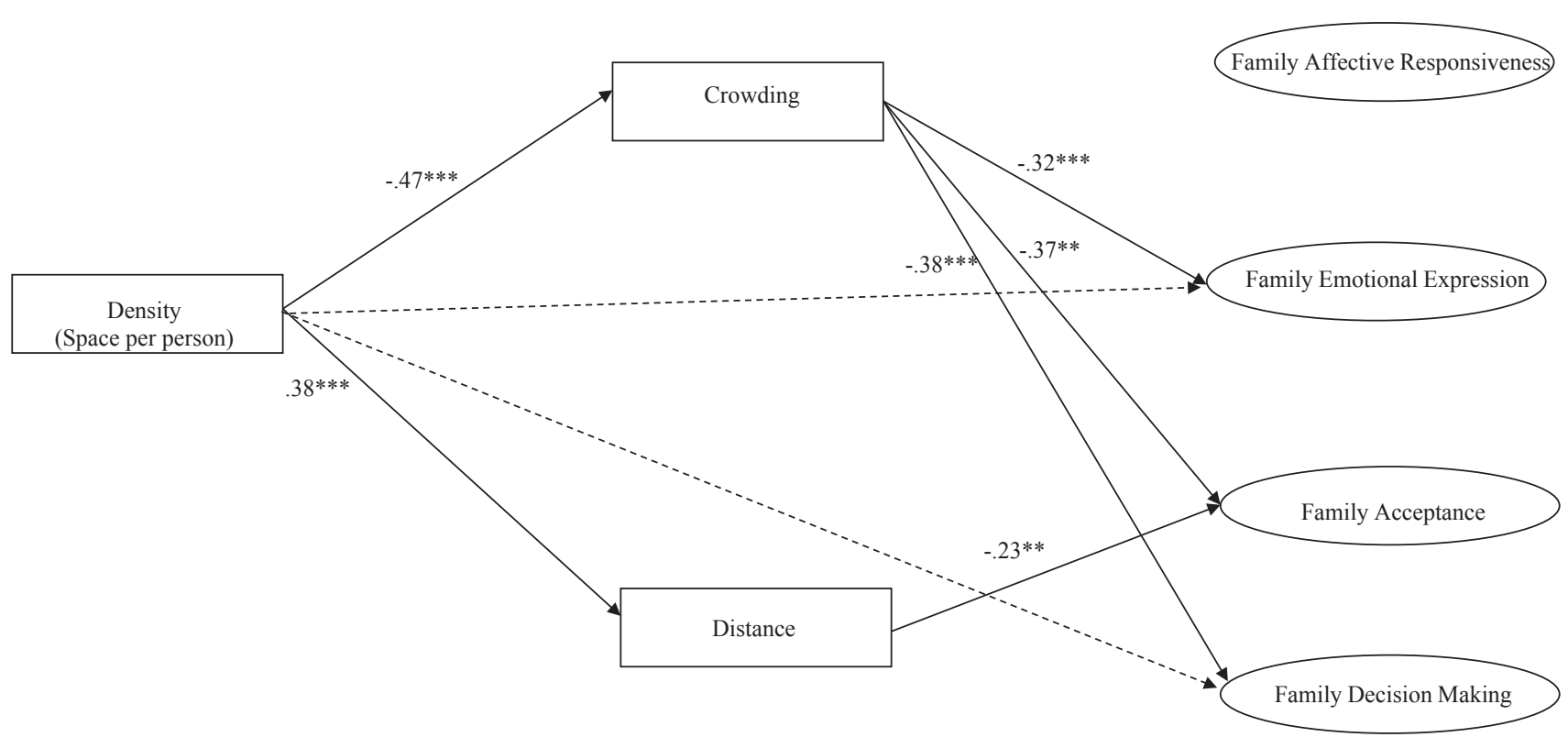

Fig. 1. Structural Equation Model

Model Fit: $\chi^{2}=193.04, \mathrm{p}<.01 ; \mathrm{CFI}=0.95$; TLI $=0.93$; $\mathrm{RMSEA}=0.05$

Standardized Indirect Effects:

Density $\rightarrow$ Family Emotional Expression $=.11$ *

Density $\rightarrow$ Family Decision-Making $=0.15^{* *}$.

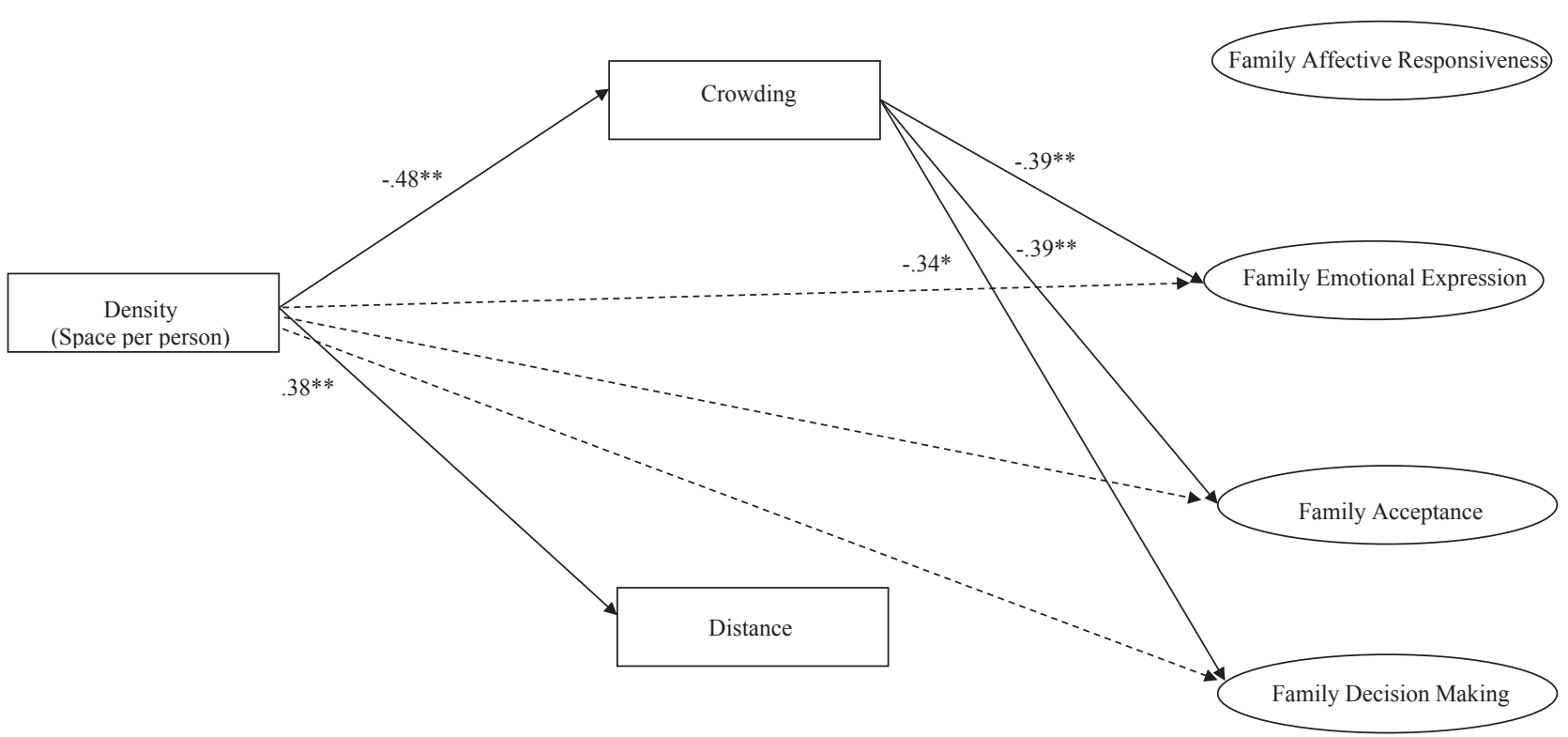

Fig. 2. Results of Multiple Group Analysis: Parents of young girls

Standardized Indirect Effects:

Density $\rightarrow$ Family Emotional Expression $=.23 *$

Density $\rightarrow$ Family Acceptance $=.22 * *$

Density $\rightarrow$ Family Decision Making $=0.17, p=.05$.

their living space is more dense but, conversely, having more space per person may encourage individuals to open up and engage in more positive interactions with one another.

Although the results regarding direct effects between density and family functioning are important, it should be noted that they were mediated by parents' perceptions of their space. Thus, it appears that perceptions of being too crowded and, respectively, too distant from others are extremely important in understanding how space influences family functioning within the home. Specifically, as space per person increased, felt crowding decreased, and as space per person increased mothers' perceptions of the family being too distant within their home increased. In turn, results revealed that perceptions of crowding, for both mothers of sons and mothers of daughters, were linked to lower levels of family emotional expressiveness, acceptance, and decisionmaking, while distance negatively predicted family acceptance. Further, perceptions of distance, for boys, were linked to lower levels of family affective responsiveness, emotional expression, and acceptance.

These findings underscore the notion that perceptions of how one feels about the space within the home environment negatively impacts family dynamics. These findings further add to a growing body of work 


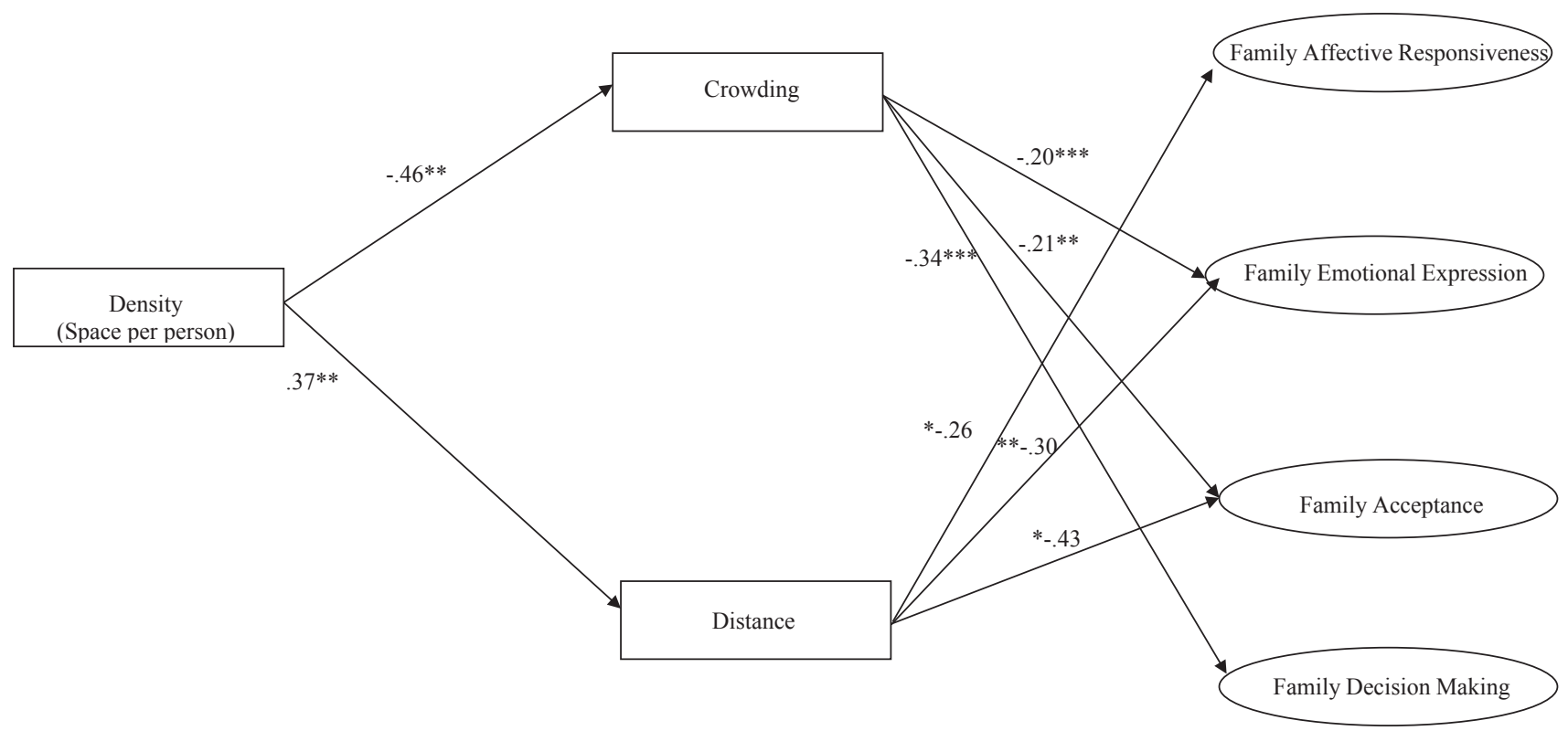

Fig. 3. Results of Multiple Group Analysis: Parents of young boys

No indirect effects for this model.

suggesting that perceptions of one's space tend to have more of an impact on individuals and groups, including families, than does the actual physical properties of the space (Baum \& Koman, 1976; Hanscombe, Haworth, Davis, Jaffee, \& Plomin, 2010). Indeed, there is a well-established body of evidence that actual aspects of space, such as high density settings (e.g., classrooms, homes, child-care centers), impede individual well-being of children (e.g., Maxwell, 1996, 2003; Saegert, 1982) but also a growing body of work showing it negatively affects interpersonal functioning including within the home (e.g., Evans et al., 1999). However, much of the work on the role of perceptions of space has been conducted in settings such as prisons (e.g., Schaeffer et al., 1988), public transportation (Evans \& Wener, 2007), and hospitals (Brummett et al., 2001) so the results of the present study are important in that they add to the growing understanding of the ways in which perceptions of space may play an important role in mediating, or explaining, how actual space influences important processes that occur in the home. Specifically, the findings suggest that either feeling too close or too spread out within the actual space that individuals find themselves may influence how they interact with others including their own families.

It may be that as perceived crowding increases and stimulation levels increase, responding to family members (i.e., accepting them, expressing emotion with them, or making decisions together) in calm, kind, patient ways may become more difficult. Instead of helping each other, they may begin to bother each other when they do not have sufficient personal space. It is important to note that so many of the aspects of family functioning examined in this study tapped the emotional climate of the interactions (e.g., emotional expression). It has long been postulated that crowding tends to intensify emotions (Freedman, 1975) such that even just minor negative emotion-invoking issues that typically arise daily in family life may be amplified when one feels crowded to the point that individuals become angry with each other, emotionally dysregulated, and, as a result, unable to work things out together. Obviously, not all parents or children will become emotionally overwhelmed as a result of feeling crowded. There are numerous factors (e.g., cultural, social, individual) that influence individuals' reaction to crowding (see Baum \& Paulus, 1987). However, the findings from this study suggest that parents of young children, who are already just learning to control and appropriately express their emotions, may be particularly at risk if they feel crowded in their living space. Hence, future work should examine whether there are unique individual factors (personality, ability to regulate emotions, temperament, etc.) that might differentiate those individuals who do or do not feel crowded and exposed (whether physically or emotionally) in certain types of space, and then, in turn, how these individual factors, in both parents and children, may affect the way in which perceptions of crowding influence family functioning.

In addition to the adverse effects of perceived crowding, the findings of the present study suggest that, for mothers of sons, feeling too spread out from family members within the home adversely affects family functioning, particularly family affective responsiveness, emotional expression, and acceptance. This suggests that, as noted in past work (e.g., Miller \& Maxwell, 2003), when considering the home, bigger is not necessarily better. The present study supports this idea and specifically reinforces the notion that excessive home space (exceeding the needs of occupant load) may discourage healthy interactions for some families, in this case, parents of young boys. Perhaps family members feel disconnected from each other due to an overabundance of space or physical barriers, such as walls and doors. Similarly, family members may not feel the need to interact with one another if everyone has his or her own space (e.g., wing of the home), negating the need to "rub shoulders" or interact with family members and, thereby, negatively impacting feelings of acceptance and closeness. Again, though, the important result of the study is that it is feeling too spread out, rather than actual indices of space, that influence family functioning. It is also important to remember that the findings related to perceived distance were pronounced for parents of sons. There is work suggesting that, even early in life, relationships with others are more important to girls than boys (Chodorow, 1989; Gilligan, 1982; Huston, 1983; Miller, 1986). Hence, regardless of space, girls may gravitate towards other people in order to form relationships with them. Boys, on the other hand, may not be as inclined towards relationship and, therefore, go where the space takes them (i.e., spread them out in the house), as it were, causing parents of boys to take note of the distance. These explanations are purely speculative but the different findings for parents of sons versus daughters certainly call for more work to examine the role of gender in the ways in which space and perceptions of space within the home environment influence the processes that occur therein.

Taken together, the findings of the present study suggest that actual 
home density, as well as feeling too crowded or too distant within the residential environment, impact the ways families interact. The amount of space per person was related to felt crowding (negatively) and distance (positively), and both crowding and distance impacted family functioning negatively. Ultimately, the actual home environment provides a number of important affordances that can impact individual perceptions, and these perceptions can subsequently impact family interactions. Thus, it is important for those who study, design, and live in residential settings to consider the human implications of both actual and perceptual elements of space.

\subsection{Implications}

Findings of the present study might be useful for families, designers/ architects, and researchers as they attempt to create environments that afford successful family interactions. As home factors, both actual and perceived, were found to influence family functioning, it may be beneficial for those who work with the actual space of a house to seek to mitigate the negative effects of perceived spatial imbalance. Though actual structural constraints of the home and spatial dimensions may be hard and expensive to change, designers and homeowners may seek to alter the perception of the existing home environment. Some researchers have suggested that feelings of perceived crowding can be eliminated by intentional arrangement of furniture and organization (Evans \& McCoy, 1998; Kopec, 2006; Wilson \& Boehland, 2005). Others have suggested that spatial organization, such as architectural depth, may be a buffer to crowding effects (Evans et al., 1996). Families may find that they can alter the perception of density by using décor and accessories, such as mirrors, light paint, and visually light weighted furniture, to mitigate detrimental effects of perceived crowding. These suggestions may assist families and those who design their home environments to make the home a more affording space without having to redistribute structural constraints (e.g., walls).

Additionally, it may benefit families and designers to encourage individuals to incorporate areas of personal identity within a home, such as bedrooms, desk space, offices, relaxing nooks, creative centers, and so forth, to help residents feel that they have a place of retreat in attempt to battle the effects of perceived crowding. Perhaps certain home layouts (e.g., open floor plan) when executed properly and including retreat potential, can alter the perception of feeling trapped, crowded, or even too far apart from other people.

The findings of the present study may also be of use to therapists and researchers. Since perceptions regarding space appear to play an important role in family interactions, therapists may be able to assist families to deliberately weigh what makes their home feel less crowded and distant and help individuals to recast their perception in more positive ways. Finally, researchers may benefit from the findings of this study as they seek to better understand the multiple factors that influence family functioning, by taking into account the role of the physical environment as another dynamic element of the family system.

\subsection{Limitations and future directions for research}

This study extends previous research by providing insight into how actual elements of the home environment contribute to influence perceived environmental elements, and, in turn, how these cognitions, or perceptions, influence family interactions. Despite the contributions it makes, the study is not without its limitations. First, as noted previously, causality can only be inferred due to the cross-sectional and correlational nature of the data. Longitudinal and experimental work is needed to better understand directionality in the relations found between variables in this study. Second, it is possible that by that asking questions about space and density the purpose of the study may have been too obvious and thus introduced a common source bias that skewed the results. Because this study was drawn from a larger project, parents filled out a rather large battery of measures assessing a variety of variables. Hence, the various questions were interspersed throughout the questionnaire so we believe it would be difficult to determine from all of those questions the specific research questions being addressed in this study. Nevertheless, future work should replicate the current findings. Third, the current sample represents a small portion of the world's cultural and socioeconomic environmental experiences; people have widely varying housing, density, crowding, and distance realities and expectations. In this respect, additional work is needed to demonstrate how regional and/or cultural factors may likewise influence persons' perceptions of their home environments and whether contextual variants further impact linkages between family space and family functioning. Hence, a great deal of future work is needed to more carefully explicate the potential contribution of cultural factors as they relate to family space across a variety of regional, cultural, and ethnic settings.

Next, income was used as a control variable in the study as it probably plays a rather important role in the amount of space a family has available to them. However, future work may want to more fully investigate (not just control) the role of income as a factor in how families perceive their space, develop expectations regarding space, and deal with the stress and emotions possibly resulting from their space. Also, we were unable to verify the amount of square feet that was reported. Future work should attempt to get more accurate and verifiable measures of square feet. It will also be important for future research to consider potential variations in perceived spatial preferences across gender, age, and family stage of life (Aiello, Epstein, \& Karlin, 1975; Blaauboer \& Mulder, 2010; Campagna, 2016; Hasell, Peatross, \& Bono, 1993). Such work may wish to examine the effects of spatial features in relation to the gender composition of a family, and not just individual gender preferences (e.g., families comprised of father, mother, four daughters, may react to space differently than a family composed of a father, mother, and two sons). To do this, more work is needed that employs fathers as it would also be important to examine potential similarities and differences between mothers and fathers perceptions of family space to account for ways men and women may view the same living space.

Finally, the intersection between family interaction and home spaces is an area that also needs additional attention. Maxwell (2003) stated that "family togetherness is more a function of what's going on in a room than the room itself" (p. 1); thus, it will be important to determine the extent to which additional physical and perceptual elements of residential spaces (perhaps including stair abundance, shared private space such as bedrooms, ceiling height, or available outside space) afford the preferable kinds of familial interactions. Further research also may investigate the mediating and moderating influences at work that more deeply explain why crowding influences family functioning so significantly (i.e., stress of individuals and families as a whole, learned affective tendencies, parenting styles, mental health, etc.).

\section{Conclusion}

This study aimed to increase understanding of the ways in which the environment shapes family relationships. Home environments affect the ways many feel about their personal space, and thus the home has the potential to influence family relationships. With an eye toward the future, shaping a home that helps residents feel secure, with respected privacy and adequate social stimulation, can eliminate potentially harmful consequences for the family. Families, designers, and researchers can benefit from being aware of the relational consequences the come with home elements of density, crowding, and distance, and make efforts to create environments that support their goals.

\section{References}

Aiello, J. R., Epstein, Y. M., \& Karlin, R. A. (1975). Field experimental research on human 
crowding. Journal of Applied Social Psychology, 5, 34-53.

Baum, A., \& Koman, S. (1976). Differential response to anticipated crowding: Psychological effects of social and spatial density. Journal of Personality and Social Psychology, 34, 526-536.

Baum, A., \& Paulus, P. (1987). Crowding. In D. Stokols, \& I. Altman (Eds.). Handbook of environmental psychology (pp. 533-570). New York: John Wiley.

Bell, P. A., Greene, T. C., Fisher, J. D., \& Baum, A. (2001). Environmental psychology (5th ed.). Fort Worth: Harcourt College Publishers.

Belsky, J., Bakermans-Kranenburg, M. J., \& van IJzendoorn, M. H. (2007). For better and for worse: Differential susceptibility to environmental influences. Current Directions in Psychological Science, 16, 300-304.

Blaauboer, M., \& Mulder, C. H. (2010). Gender differences in the impact of family background on leaving the parental home. Journal of Housing and the Built Environment, 25, 278-300.

Brummett, B. H., Barefoot, J. C., Seigler, I. C., Clapp-Channing, N. E., Lytle, B. L., Bosworth, H. B., et al. (2001). Characteristics of socially isolated patients with coronary artery disease who are at elevated risk for mortality. Psychosomatic Medicine, $62,267-272$

Campagna, G. (2016). Linking crowding, housing inadequacy, and perceived housing stress. Journal of Environmental Psychology, 45, 252-266.

Chemero, A. (2003). An outline of a theory of affordances. Ecological Psychology, 15, 181-195.

Chodorow, N. (1989). Feminism and psychoanalytic theory. New Haven, CT: Yale University Press.

Cohen, S., Krantz, D., Evans, G., Stokolos, D., \& Kelly, S. (1981). Aircraft noise and children: Longitudinal and cross-sectional evidence on adaptation to noise and the effectiveness of noise abatement. Journal of Personality and Social Psychology, 40, 331-345.

Coldwell, J., Pike, A., \& Dunn, J. (2006). Household chaos-links with parenting and child behaviour. Journal of Child Psychology and Psychiatry, 47, 1116-1122.

Dumas, J. E., Nissley, J., Nordstrom, A., Smith, E. P., Prinz, R. J., \& Levine, D. W. (2010). Home chaos: Sociodemographic, parenting, interactional, and child correlates. Journal of Clinical Child and Adolescent Psychology, 34, 93-104.

Else-Quest, N. M., Hyde, J. S., Shibley Goldsmith, H. H., \& Van Hulle, C. A. (2006). Gender differences in temperament: A meta-analysis. Psychological Bulletin, 132, $33-72$.

Emerson, E., Robertson, J., Gregory, N., Hatton, C., Kessissoglou, S., Hallam, A., et al. (2000). Treatment and management of challenging behavior in residential settings. Journal of Applied Research in Intellectual Disabilities, 13, 197-215.

Epstein, N. B., Baldwin, L. M., \& Bishop, D. S. (1983). The McMaster family assessment Device. Journal of Marital and Family Therapy, 9, 171-180.

Evans, G. W. (2006). Child development and the physical environment. Annual Review of Psychology, 57, 423-451.

Evans, G. W., \& Cohen, S. (1987). Environmental stress. In D. Stokols, \& I. Altman (Eds.). Handbook of environmental psychology (pp. 571-610). New York: John Wiley.

Evans, G. W., Lepore, S. J., \& Schroeder, A. (1996). The role of interior design elements in human responses to crowding. Journal of Personality and Social Psychology, 20, 41-46.

Evans, G. W., Lercher, P., \& Kofler, W. W. (2002). Crowding and children's mental health: The role of house type. Journal of Environmental Psychology, 22, 221-231.

Evans, G. W., \& Maxwell, L. (1997). Chronic noise exposure and reading deficits: The mediating effects of language acquisition. Environment and Behavior, 29, 628-656.

Evans, G. W., Maxwell, L. E., \& Hart, B. (1999). Parental language and verbal responsiveness to children in crowded homes. Developmental Psychology, 35(4), 1020-1023.

Evans, G. W., \& McCoy, J. M. (1998). When buildings don't work: The role of architecture in human health. Journal of Environmental Psychology, 18, 85-94.

Evans, G. W., \& Wener, R. E. (2007). Crowding and personal space invasion on the train: Please don't make me sit in the middle. Journal of Environmental Psychology, 27, 90-94.

Farrow, A., Taylor, H., \& Golding, J. (2010). Time spent in the home by different family members. Environmental Technology, 18, 605-613.

Fiese, B. H., Tomcho, T. J., Douglas, M., Josephs, K., Poltrock, S., \& Baker, T. (2002). A review of 50 years of research on naturally occurring family routines and rituals: Cause for celebration? Journal of Family Psychology, 16, 381-390.

Freedman, J. L. (1975). Crowding and behavior. Oxford, England: W. H. Freedman.

Gabe, J., \& Williams, P. (1986). Is space bad for your health? The relationship between crowding in the home and emotional distress in women. Sociology of Health \& Illness, 8, 351-371

Gibson, J. J. (1977). The theory of affordances. In R. E. Shaw, \& J. Bransford (Eds.). Perceiving, acting, and knowing. Hillsdale, NJ: Erlbaum.

Gilligan, C. F. (1982). A different voice. Cambridge, MA: Harvard University Press.

Gorman-Smith, D., Henry, D. B., \& Tolan, P. H. (2004). Exposure to community violence and violence perpetration: The protective effects of family functioning. Journal of Clinical Child and Adolescent Psychology, 33, 439-449.

Hanscombe, K. B., Haworth, C. M. A., Davis, O. S. P., Jaffee, S. R., \& Plomin, R. (2010). The nature (and nurture) of children's perceptions of family chaos. Learning and Individual Differences, 20, 549-553.

Hasell, M. J., Peatross, F. D., \& Bono, C. A. (1993). Gender choice and domestic space: Preferences for kitchens in married households. Journal of Architectural and Planning Research, 10, 1-22.

Heft, H. (2001). Ecological psychology in context: James gibson, roger barker, and the legacy of william james' radical empiricism. Mahwah, NJ: Lawrence Erlbaum Associates.

Hooper, D., Coughlan, J., \& Mullen, M. R. (2008). Structural equation modeling: Guidelines for determining model fit. Electronic Journal of Business Research Methods, 6, 53-60.

House, J. S. (2001). Social isolation kills, but how and why? Psychosomatic Medicine, 63(2), 273-274.

Hu, L. T., \& Bentler, P. M. (1999). Cutoff criteria for fit indexes in covariance structure analysis: Conventional criteria versus new alternatives. Structural Equation Modeling, 6(1), 1-55.

Huston, A. C. (1983). Sex-typing. In P. Mussen, \& E. M. Hetherington (Eds.). Handbook of child psychology: Vol. 4, Socialization, personality, and social development (pp. 387467). (4th ed.). New York: Wiley.

Kaminoff, R., \& Proshansky, H. M. (1982). Stress as a consequence of the urban physical environment. In L. Goldberger, \& S. Beznitz (Eds.). Handbook of stress (pp. 380-409). New York: Free Press.

Knowles, E. S. (1983). Social physics and the effects of others: Tests of the effects of audience size and distance on social judgments and behavior. Journal of Personality and Social Psychology, 45, 1263-1279.

Kopec, D. A. (2006). Environmental psychology for design. New York: Fairchild.

Kopec, D., \& LaCapra, D. (2008). Designing stimulating environments for infants and toddlers. Journal of Interior Design, 33, 50-62.

LeBlanc, M., Self-Brown, S., Shepard, D., \& Kelley, M. L. (2011). Buffering the effects of violence: Communication and problem-solving skills as protective factors for adolescents exposed to violence. Journal of Community Psychology, 39, 353-367.

Lewin, K., Heider, F., \& Heider, G. M. (1936). Principles of topological psychology. New York, New York: McGraw-Hill.

Lewis, E. L., \& Turner, C. S. (2006). Housing decisions. Tinley Park, Illinois: GoodheartWilcox.

Matheny, A. P., Wachs, T. D., Ludwig, J. L., \& Phillips, K. (1995). Bringing order out of chaos: Psychometric characteristics of the confusion, hubbub, and order scale. Journal of Applied Developmental Psychology, 16, 429-444.

Maxwell, L. E. (1996). Multiple effects of home and day care crowding. Environment and Behavior, 28, 494-511.

Maxwell, L. E. (2003). Home and school density effects on elementary school children: The role of spatial density. Environment and Behavior, 35, 566-578.

McAndrew, F. T. (1993). Environmental psychology. Pacific Grove, CA: Brooks/Cole Publishing Company.

Michaels, C. F. (2003). Affordances: Four points of debate. Ecological Psychology, 15 $135-148$.

Miller, J. B. (1986). Toward a new psychology of women ( $2^{\text {nd }}$ ed.). Boston: Beacon Press.

Miller, B. C., \& Gerard, D. (1979). Family influences on the development of creativity in children: An integrative review. Family Relations, 28, 295-312.

Miller, A. S., \& Maxwell, L. E. (2003). Exploring the role of home design in fostering family interaction: The use of programming methods in research. Journal of Interior Design, 29, 50-65.

Miller, P. C., Shim, J. E., \& Holden, G. W. (1998). Immediate contextual influences on maternal behavior: Environmental affordances and demands. Journal of Environmental Psychology, 18, 387-398.

Preacher, K. J., \& Hayes, A. F. (2008). Asymptotic and resampling strategies for assessing and comparing indirect effects in multiple mediator models. Behavior Research Methods, 40, 879-891.

Rubin, K. H., Nelson, L. J., Hastings, P., \& Asendorpf, J. (1999). The transaction between parents' perceptions of their children's shyness and their parenting styles. International Journal of Behavioral Development, 23, 937-958.

Saegert, S. (1982). Environment and children's mental health: Residential density and low income children. In A. Baum, \& J. E. Singer (Vol. Eds.), Handbook of psychology and health: Vol. 2, (pp. 247-271). Hillsdale, NJ: Lawrence Erlbaum.

Schaeffer, M. A., Baum, A., Paulus, P. B., \& Gaes, G. G. (1988). Architecturally mediated effects of social density in prison. Environment and Behavior, 20, 3-19.

Shamama-tus-Sabah, S., \& Gillani, N. (2011). Conduct problems, social skills, study skills, and home chaos in school children: A correlational study. Pakistan Journal of Psychological Research, 26, 201-215.

Thornock, C. M., Nelson, L. J., Robinson, C. C., \& Hart, C. H. (2013). The direct and indirect effects of home clutter on parenting. Family Relations, 62, 783-794.

Wachs, T. D. (1979). Proximal experience and early cognitive-intellectual development: The physical environment. Merrill-Palmer Quarterly of Behavior and Development, 25 , $3-41$.

Wachs, T. D. (1988). Relevance of physical environment influences for toddler temperament. Infant Behavior and Development, 11, 431-445.

Wachs, T. (1989). The nature of the physical microenvironment: An expanded classification system. Merrill-Palmer Quarterly, 35(4), 399-419.

Wachs, T., \& Chan, A. (1986). Specificity of environmental actions as seen in physical and social environmental correlates of three aspects of twelve-month-old infants' communication performance. Child Development, 57, 1464-1474.

Wilson, A., \& Boehland, J. (2005). Small is beautiful. Journal of Industrial Ecology, 9, 277-287.

Wohlwill, J. F. (1974). Human adaptation to levels of environmental stimulation. Human Ecology, 2, 127-147.

Zigler, E., \& Finn Stevenson, M. (1993). Children in a changing world: Development and social issues. Pacific Groves, CA: Brooks/Cole. 